\title{
Competency Maps: An Effective Model to Integrate Professional Competencies across a STEM Curriculum
}

\begin{abstract}
Curricula designed in the context of the European Higher Education Area need to be based on both domain-specific and professional competencies. Whereas universities have had extensive experience in developing students' domain-specific competencies, fostering professional competencies poses a new challenge we need to face. This paper presents a model to globally develop professional competencies in a STEM degree program, and assesses the results of its implementation after four years. The model is based on the use of competency maps, in which each competency is defined in terms of competency units. Each competency unit is described by their expected learning outcomes at three domain levels. This model allows careful analysis, revision and iteration for an effective integration of professional competencies in domain-specific subjects. A global competency map is also designed, including all the professional-competency learning outcomes to be achieved throughout the degree. This map becomes a useful tool for curriculum designers and coordinators. The results were obtained from four sources: 1) students' grades (classes graduated from 2013 to 2016, the first four years from the new Bachelor's Degree in Informatics Engineering at the Barcelona School of Informatics); 2) students' surveys (answered by students when they finished the degree); 3) the government employment survey, where former students evaluate the satisfaction of the received training in the light of their work experience; and 4) the Everis Foundation University-Enterprise Ranking, answered by over 2000 employers evaluating their satisfaction regarding their employees' university training, where the Barcelona School of Informatics scores first in the national ranking. The results show that competency maps are a good tool for developing professional competencies in a STEM degree.
\end{abstract}

Keywords: STEM education, Engineering education, professional competencies, professional skills, academic programs, curriculum design, competency maps, competency units, learning outcomes. 


\section{INTRODUCTION}

In the 90's, interesting academic debate was raised about the need to develop students' professional skills ${ }^{1}$ in university degree curricula. Scholars like Hodson (1992) argued that "the skills-based approach was pedagogically dangerous because it encourages bad teaching”. Nowadays, this debate has become obsolete, and university and employers agree on the importance of training graduates in professional competencies. The term "professional competencies" is used to refer to competencies that graduate students will need to acquire for their profession beyond the technical knowledge required (known as “technical competencies"). While technical competencies guarantee the acquisition of knowledge in each area, professional competencies enforce transversal skills and practices that are appropriate for most areas and can be applied to a variety of jobs, situations or tasks (Gardelliano, 2002). As an example, programming is a technical competency while teamwork is a professional one.

It must be noted that the authors prefer to use the term "competency" instead of "skill". Although both terms are often used interchangeably, "skill" is defined as the ability to apply knowledge and use expertise to complete tasks and solve problems, whereas "competency" refers to the proven ability to use knowledge and personal, social, and/or methodological abilities in professional and personal development (European Parliament, 2008). Thus, competency can be understood as the combination of knowledge and experience (Basselier, 2003).

\section{A. The need for professional competencies in STEM studies}

Since the beginning of this century, competency-based approaches have been promoted in a number of studies that emphasize the benefits of global instruction. Among them, Rainey (2002) claims that, if a degree program focuses on solving today's problems with today's technologies, this program is quickly outdated, specially in the STEM (Science, Technology, Engineering and Mathematics) environment. Instead, students need to develop professional competencies, since the training needs of a STEM graduate not only should consider technical competencies, but must also be viewed from a multidisciplinary perspective. $\mathrm{Hu}$ (2003) insists on the importance of fostering professional competencies, and points out that a curriculum must be designed to provide students with solid fundamental knowledge, and to teach them how to learn. It is more important to have a curriculum that integrates knowledge and competencies

\footnotetext{
${ }^{1}$ In some contexts, the terms "hard" and "soft" skills are used. We consider the term technical and professional (also called generic or transversal) more appropriate.
} 
to be applied in new situations than one that teaches vanguard technology but may become obsolete in a few years.

In the same line, other studies explore the importance of professional competencies from different perspectives. Newrock and Tovar (2005) identify employers' requirements with respect to professional competencies by interviewing industry leaders. To succeed in the world of business, STEM graduates need much more than excellent technical knowledge. More specifically, they must be able to communicate their ideas, they need to understand what corporate ethics and personal ethics mean, they need to develop social skills and manners, and they need to learn how to respect their peers. Taraman (2005) also claim that success or failure in the educational process should be measured through the set of competencies students need to acquire. Furthermore, the UNESCO International Centre for Engineering Education (UICEE) report ${ }^{2}$ reveals that STEM graduates require a wide range of professional competencies, in addition to a high degree of technical competence (Riemer, 2007).

In order to know employers' opinion about which competencies are relevant in Catalonia (Spain), the Catalan University Quality Assurance Agency ${ }^{3}$ (AQU) conducted a survey ${ }^{4}$ at the end of 2014. This study (AQU, 2014) is comparable with other European surveys, such as Eurobarometer ${ }^{5}$, but it provides local data. The survey's universe consisted of 16,757 companies with production activities in Catalonia. The sample obtained was 1,325 companies, representing a response rate of $7.91 \%$ and a sampling error of 2.64\%. The study is not focused on STEM graduates, but includes all disciplines.

AQU's survey contributes to stressing the importance of professional competencies in tertiary education, according to participants' opinions. Fig. 1 compares the importance given by employers to some competencies and their degree of satisfaction with graduates' competencies. The comparison ratio indicated by these values suggests that universities should dedicate more effort to training some competencies. The main highlights extracted from the survey are the following:

- The overall satisfaction with the competencies of hired graduates was 7 out of 10 (medium to high). Although the rating varied across competencies, all of them were given at least a pass mark of 5 .

\footnotetext{
${ }^{2}$ http://www.wiete.com.au/journals/GJEE/Publish/vol8no1/PudlowskiDarvall.pdf. Last accessed March 2018.

${ }^{3} \mathrm{http}: / / \mathrm{www}$.aqu.cat. Last accessed March 2018.

${ }^{4}$ http://www.aqu.cat/doc/doc_69192241_1.pdf. Last accessed March 2018.

${ }^{5}$ http://ec.europa.eu/public_opinion/flash/fl_304_en.pdf. Last accessed March 2018.
} 
- On a scale from 0 to 10 , the competencies that employers considered to be most important were responsibility at work (8.9), the ability to learn (8.4) and teamwork (8.3). The least important were leadership (6.6) and negotiation skills (6.4).

- $\quad$ On a scale from 0 to 10 , the graduates' competencies which employers were most satisfied with were computer skills (7.9), responsibility at work (7.6), teamwork (7.5), theoretical learning (7.2), and the ability to learn (7.0). They were least satisfied with leadership (5.8) and negotiation skills (5.7).

- The degree of satisfaction with graduates' competencies did not vary greatly according to the branch of economic activity or the size of the enterprise or institution, except for foreign language skills.

As Fig. 1 shows, the largest comparison ratio between the importance given by employers to graduates' competencies and their degree of satisfaction corresponds to problem solving (-1.7), practical skills (-1.6) and the ability to generate new ideas (-1.5). However, professional competencies in general should be trained in more depth at tertiary level, since most of them are still weak according to employers' opinions. For example, responsibility at work scores 8.9 in importance against 7.6 in satisfaction (-1.3), learning ability achieves 8.4 against $7.0(-1.4)$, and communication skills scores 8.00 against $6.6(-1.4)$.

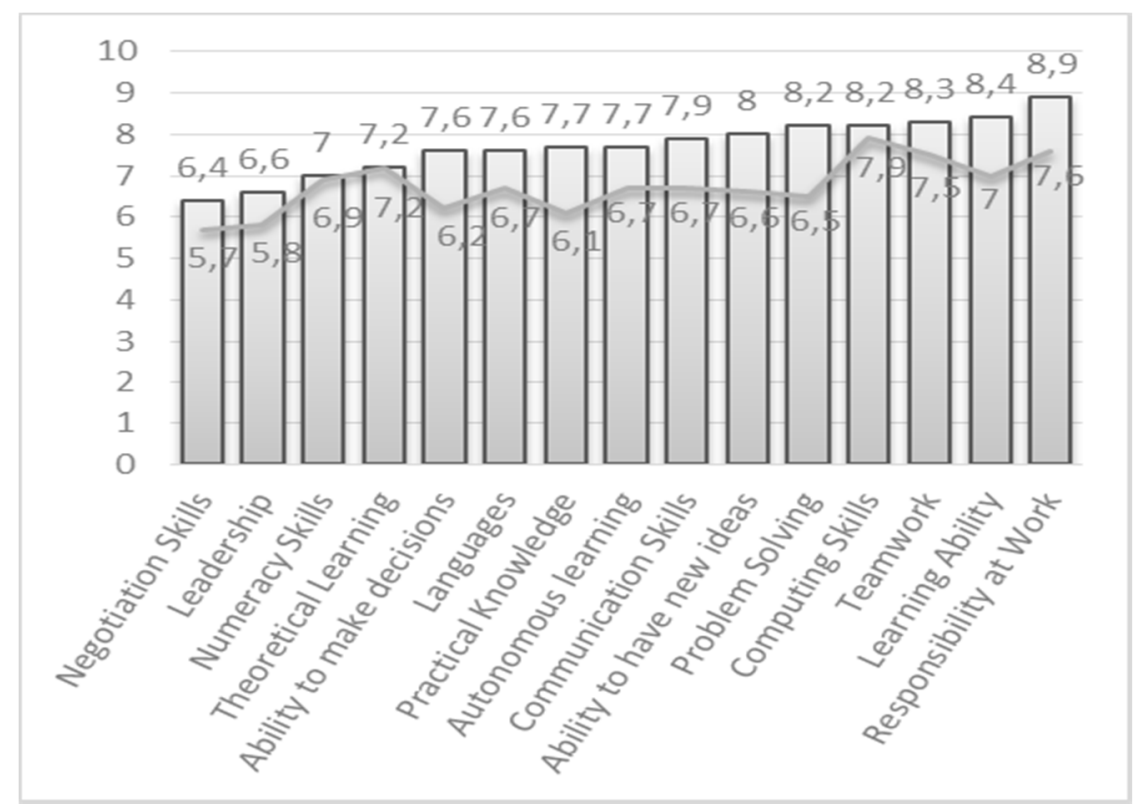

Fig. 1. Employers' opinion: importance given to competencies (bars) against level of training received by recent graduates (line).

B. $\quad$ Training professional competencies in Europe and U.S. STEM universities 
In the mid-90s, prior to the creation of the European Higher Education Area (EHEA), university curricula in Europe focused on the development of technical competencies, without paying much attention to professional competencies. These competencies were only included occasionally in some subjects, and were rarely assessed in STEM curricula. This situation was common to both European and American universities. According to observed needs with respect to graduates' professional competencies, European and American universities have tried to address professional competencies training in recent years. As this work is focused on engineering studies, we will put the stress on engineering initiatives. Some criteria in sciences and mathematics curriculum design can be different from engineering criteria, but the competencies required and the difficulties to integrate them in the curriculum are similar. This is mainly because most STEM programs are based on acquiring the rigorous technical knowledge students need to succeed in their profession, ignoring professional competencies (Taylor 2016).

In order to identify the real needs of engineering professionals and address them most appropriately, the ABET accreditation system (ABET, 2017) was introduced into American engineering education in the mid-90s. It involved a significant change in the criteria established for engineering programs to be accredited since it introduces professional skills in the curricula.

Another initiative to meet engineering students' needs was proposed in 2000 by the Department of Aeronautics and Astronautics at the MIT. They started the CDIO (Conceive, Design, Implement, and Operate) project to encourage the development of abilities required in real-world engineering situations (Crawley, 2008). Other universities and departments quickly joined this initiative, and it is currently a widely used methodology in STEM education (Crawley, 2014). The CDIO project started after a thorough analysis of university contents and practice, since an important gap between industry requirements and the contents of engineering curricula was observed. Universities focused their efforts on research activities, and technical contents became more and more relevant in syllabuses. As more time and effort was devoted to technical contents, other aspects were left aside, like students' personal and interpersonal skills. Therefore, the objective of the CDIO initiative was to foster students' personal and interpersonal abilities while technical competencies were maintained (as shown in Fig. 2). 


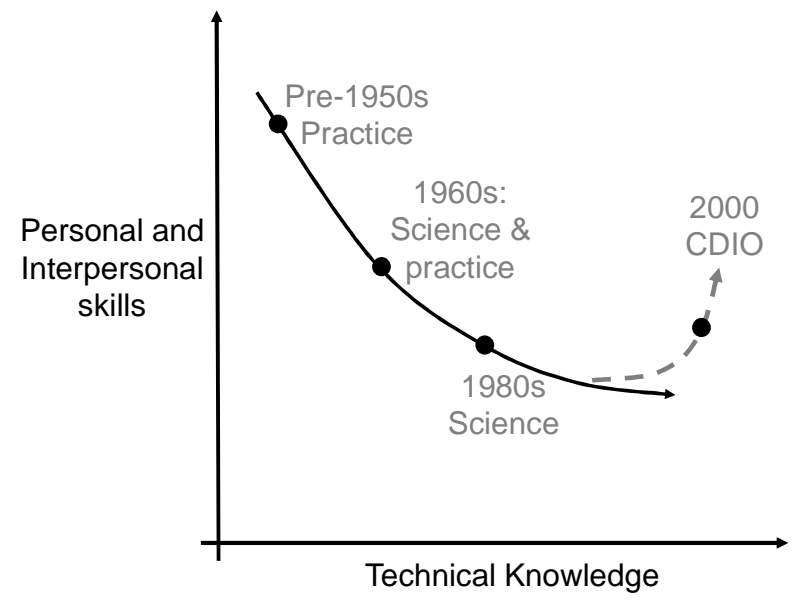

Fig. 2. CDIO objective.

As the CDIO initiative started in the U.S., the Tuning ${ }^{6}$ project was developed in Europe with similar objectives. Led by the University of Deusto (Spain), the project was supported by more than one hundred European universities. The Tuning project focuses on the design of a methodology that favors curriculum understanding and standardization among universities. The project has also been extended to Latin America (Beneitone et al, 2007).

The work developed in the first phase of Tuning defined thirty professional competencies that would be common to the academic programs included in the study, and a list of domain-specific competencies for each discipline. The thirty competencies were classified into three categories: instrumental (10), interpersonal (8) and systemic (12). All competencies were defined in depth in a report adopted by the institutions that intended to integrate professional competencies in their curricula.

Taking into account these standardization guidelines, some studies have recently explored which competencies are required from students of a STEM degree. Jang (2016) identifies 18 competencies, 7 categories of knowledge and 27 work activities important for STEM workers. An ongoing research project (Bayer, 2014) examines the US STEM education, diversity and workforce issues. In this project, a survey shows most of the skills that applicants do not possess but wish they did. Some of these skills are leadership, conflict resolution, complex problem-solving, team building, communication, and critical thinking skills.

Thus, as suggested throughout this section, there are several studies in the literature that emphasize the need to include professional competencies in engineering curricula, but much fewer studies on how to

${ }^{6}$ http://tuning.unideusto.org/tuningal. Last accessed March 2018. 
integrate them in a systematic way. In this paper, we propose a methodology to effectively integrate professional competencies in STEM curricula by using competency maps, global structures that describe the development of a given competency in the degree subjects.

\section{Integrating professional competencies across the curriculum}

Although different proposals to introduce professional competencies in a given technical subject may prove to be effective, the authors of present work believe that a global strategy is necessary to develop each competency across the curriculum. With an appropriate coordination of competency development, it is possible to set itineraries for each professional competency, where participants are aware of domain levels, learning outcomes, contents and the subjects where they are trained, as shown in Fig. 3. In this figure, each box represents a subject from year 1 to year 4 in the curriculum, and black boxes represent the subjects where a given competency is integrated.

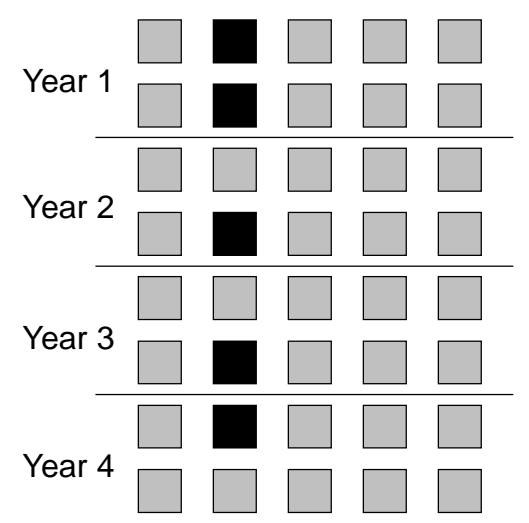

Fig. 3. Example of competency itinerary (black boxes).

Assigning professional competencies to technical subjects requires setting up domain levels and coordinating the work carried out in different courses for a given competency. This new and complex task entails careful planning. Indeed, most faculty members in undergraduate and postgraduate STEM programs have little or no experience in training professional competencies, so they find difficult to include them in their courses. Some of the professional competencies may even be more difficult to include in some technical subjects than others. For example, lecturers might find it easier to integrate communication skills or teamwork skills than ethical or social commitment skills.

In order to integrate professional competencies into degree subjects, we initially devised a hierarchical approach based on Bloom's taxonomy (Bloom, 1956). At this stage, we defined each competence in terms of three-level learning outcomes, based on the "knowledge", "comprehension", and "application" 
domain levels in Bloom's model. Each level was assigned to one or more courses, so level 1 of each competency was developed in first-year courses. Then, level 2 started in the second year and was completed in the third and fourth years if necessary. Finally, level 3 would be developed in the third and fourth years according to the specific learning outcomes of each degree. Fig. 4 illustrates this model, where each box represents one subject. In this approach, a coordinator was also assigned to each competency to help course designers and lecturers to design learning activities to practice and assess the competency.

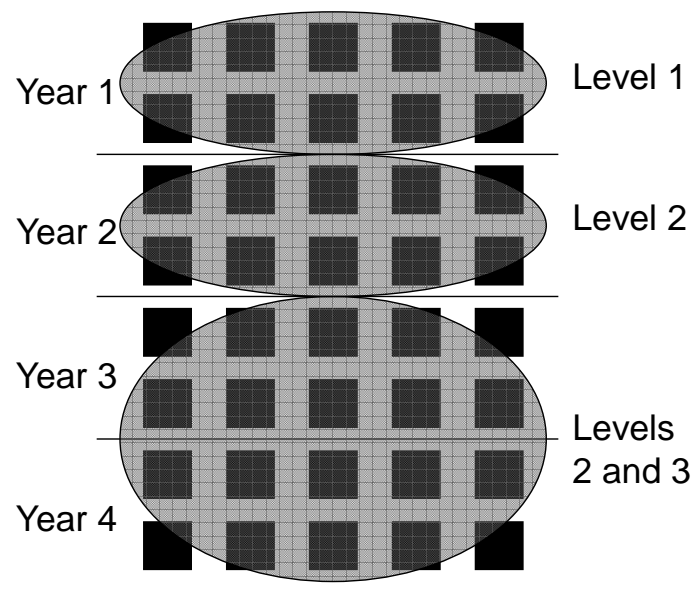

Fig. 4. Domain levels distributed in academic years.

As a starting point, this methodology provides tools for curriculum designers to integrate professional competencies into degree subjects. However, it is difficult to apply because defining a professional competency in terms of Blooms' domain levels poses some problems, i.e., a domain level is still too general to define a competency. A more accurate tool was required, so we started a new approach to refine the process of defining professional competencies, and also to assign learning outcomes to subjects in a more accurate way.

Thus, although regarding technical competencies the classical three-level hierarchical approach is effective, it appears to be less appropriate for the integration of professional competencies. The subjects focusing on a technical competency itinerary in the first and second years develop and evaluate learning outcomes at the lowest domain levels of the learning taxonomy, while the subjects of final courses develop and evaluate the highest domain levels. However, in the case of professional competencies the domain levels are not as clear as in technical competencies, and it is quite complex to define just three domain levels for a whole competency. It was observed that some specific learning outcomes for a given competency at a low domain level actually required to achieve some previous learning outcomes at higher 
levels. In addition, some specific learning outcomes could overlap across different domain levels. So, we decided to devise a procedure to assign learning outcomes of professional competencies across the curriculum subjects in a systematic way to guarantee that these competencies are acquired.

The remainder of this article develops all the details of our model and its implementation as follows. Section II presents the identified research questions and the methodology used to address them. Section III reviews some of the relevant related studies. In Section IV, the context in which this work has been developed is presented. The proposal describing how to integrate professional competencies in STEM curricula is detailed in Section V. Section VI presents and discusses some results, and finally, Section VII concludes the paper.

\section{RESEARCH QUESTIONS AND METHODOLOGY}

A. Research Questions

In the light of the difficulties previously explained to use the classic hierarchical approach to introduce professional competencies in the curriculum, we developed what we call "competency maps". To test the efficiency of our model, in this study we have posed 5 research questions:

1.- Can competency maps help to effectively distribute professional competencies across the curriculum and guarantee that all students have the opportunity to practice them?

In this paper, we present the conceptual model based on competency maps to distribute and evaluate the learning outcomes for the first four years.

2.- Do students improve their professional competencies by using competency maps as a methodology?

To answer this question, the results obtained by 384 students between 2013 and 2016 are analyzed. It is assumed that the results are a good indicator of the skills demonstrated for each professional competence.

3.- Are students satisfied with the progress made in professional competencies? Do they consider professional competencies important?

In order to look into students' opinions, we use qualitative results from a survey conducted among all students at the end of their studies.

4.- What are employers' and international evaluation agencies' views on the results obtained by graduates who have been trained with competency maps? 
Our study analyzes qualitative results from employer surveys conducted by different organizations. In addition, we also take into considerations the results of national and international accreditation surveys that evaluate the degree where competency maps have been implemented.

5.- Is there a relationship between the acquisition of technical competencies and the acquisition of professional competencies? Do students who get high academic final grades also get high grades in professional competencies, and vice versa?

To answer this last question, the degrees of 421 students who finished their studies between 2013 and 2016 (both included) are analyzed. These students account for 100\% of the first four cohorts from the Bachelor Degree in Informatics Engineering at the Barcelona School of Informatics.

\section{B. General Methodology}

In the Bachelor's Degree in Informatics Engineering at the Barcelona School of Informatics, a strategy was devised to develop and evaluate nine professional competencies. This involved the creation of a research team consisting of one coordinator for each competency (nine competence coordinators), plus a general coordinator. Our strategy also defined a methodology to implement our model in different stages and to evaluate its efficiency.

1. First, the classic hierarchical approach was used to define each of the nine professional competencies in terms of learning outcomes based on the three lower domain levels of Bloom's taxonomy (1956): knowledge, understanding and application.

2. Next, the defined learning outcomes were distributed among the subjects of the competency itinerary.

This distribution followed the classic hierarchical model: the learning outcomes corresponding to the "knowledge" level were assigned to first-year degree subjects, and those corresponding to the "understanding” and "application” levels were distributed among more advanced courses.

3. All subjects in the curriculum were assigned the task of developing and evaluating at least one professional competency. Each subject had to provide two marks: the overall grade of the subject and the grade corresponding to the professional competency developed in the course.

4. This approach was implemented for two years and it was evaluated in order to assess the progress made and identify flaws. The coordinators of each competency interacted with subject coordinators of the competency itinerary to help them to design learning activities to practice and evaluate the competency at 
the assigned domain level. The coordinators of each competency and the general coordinator met regularly (once a month during the first three years, and once every two months the following years) to share their experience and views.

5. The difficulties encountered in the application of this model led the authors to conclude that the classic hierarchical model is not the most appropriate approach to accomplish the goals to develop professional competencies. As mentioned above, learning outcomes were too general to be assigned to subjects, considering the students' needs. Accordingly, in the light of the results obtained during the first two years, a new model has been proposed to define learning outcomes more accurately by using competency maps. A competency map first defines a competency in terms of competency units. In turn, these units determine the definition of the expected learning outcomes for each competency, based on the three low domain levels of Bloom's taxonomy.

6. After carefully defining learning outcomes in each competency map, they were distributed among the different subjects of the competency itinerary, using the hierarchical approach for each competency unit. In this way, one subject may develop different competency units at different domain levels of the taxonomy. For example, one subject may focus both on the knowledge level of a particular competency unit and on the application level of another competency unit. This constitutes the main difference between the model proposed in this work and the hierarchical model.

7. Our methodology also considers evaluating the proposed model, which involves answering our research questions and reporting results. Research question 1 will be resolved throughout the design process. To answer research question 2 , the final results obtained by the students will be used, assuming that the final grades of each competency reflect the student's ability in each competency. Questions 3 and 4 will be answered qualitatively by analyzing surveys from different sources, as explained above. More specifically, question 3 will be answered with the surveys conducted among students at the end of their studies, while question 4 will look at the results of surveys conducted by different organizations and the evaluation carried out by national and international agencies to accredit the degree where competency maps have been integrated.

8. Research question 5 deserves special attention since it is related to our methods to assess students' progress in professional competencies and to analyze the implementation of our model in the light of these results. The average grade obtained by each student in each professional competency itinerary 
allows each student to have a separate global grade for each of the nine professional competencies. In addition, the grades obtained for the subjects in the itinerary allow to trace the progress made by students throughout each professional competency itinerary.

Having independent grades for domain-specific skills and for professional competencies also allows to compare both grades and to study whether a relationship exists between both of them. To study this relationship, for each student and for each professional competency, the grade of a given professional competency will be calculated as the average of the grades obtained in all the subjects of the competency itinerary (among 5 and 8 subjects in each case). The subjects are not the same for all students, since $37.5 \%$ of them are elective. As the professional competency grade is qualitative, in the discrete range A-D (A assigned to highest achievement and D to lowest), these values will be replaced by an ordinal scale (41) to obtain a professional competency grade in a numerical scale. The grade for each professional competency will subsequently be calculated as an arithmetic mean from all the numerical grades obtained by the student in his/her competency itineraries.

Separate grades will thus allow us to quantify the intensity of the relationship between the academic final grade and the grade of each professional competency. We think that, if the methodology proposed to work and evaluate professional competencies is adequate, a high level of association should be found between the academic final grade and the grades of professional competencies. Although the Pearson correlation coefficient is the most popular to provide significance information, it involves an associated correlation test that requires normal distribution. Therefore, we will first evaluate whether the professional competency grades are normally distributed by using the Shapiro-Wilk test, with a confidence level of $99 \%$. Thus, p-values smaller than 0.01 will indicate that the assessed distribution is not normal. When values appear to be normally distributed for a professional competency grade, the classic Pearson correlation coefficient between the academic final grade and the professional competency grade will be calculated. A subsequent significance test will be performed to assess whether the level of association is significantly different from zero. In contrast, when the professional competency grades appear to fail the Shapiro-Wilk test, we will use the Spearman correlation coefficient, based on ranks, which does not require normality. It assesses the relationship level in general, and it is valid even for nonlinear associations. The corresponding significance test is based on the permutation test and it is also free from technical restrictive hypothesis. In both cases, p-values of the corresponding correlation test lower than 0.01 will mean significant level of association between both grades. 


\section{RELATED WORK}

Various studies have focused on teaching and assessing professional competencies (see for instance, the comprehensive review by Shuman (2005)). Whereas ABET criteria are commonly used to drive engineering curriculum design in U.S. (Passow, 2012), in the context of the European Higher Education Area (EHEA), engineering curricula are designed in accordance with the Tuning project, based on competencies and following the requirements set by institutions. These trends have a common goal: curriculum design should place emphasis on the development of professional competencies. To achieve this purpose, two different methods have been used: specific instruction and integrative approaches.

Specific instruction consists in including specific subjects into STEM curricula for training students in professional competencies. This approach has been adopted in some programs on the basis of its benefits for students and designers. As stated by Evans and Gabriel (2007) when referring to communication skills, the specific-subject approach makes four assumptions: 1) as a skill, it is a kind of a practical knowledge; 2) because it is practical, it can be separated from the foundational knowledge of a particular subject, area, or field - in other words, it is discrete-; 3) because it is discrete, it is widely applicable, and it is generalizable across different subjects, areas, or fields; and 4) these competencies, because they are practical, discrete, and generalizable, are knowledge than can be learned once and for all. A clear example of this approach is presented by Ben-Zvi-Assaraf and Ayal (2010). They explain how to involve chemical engineering students with sustainability by means of a dedicated course on the topic. The specific-subject approach is also implemented, for example, at University of Missouri where, after detecting (with a pilot survey) the lack of pedagogical knowledge in the development of professional competencies, they included a two-semester course entitled "Preparing Engineering Faculty and Professionals", emphasizing these competencies (Mohan, 2010).

However, when professional competencies are isolated from domain-specific competencies, students may find it difficult to link these competencies with STEM-graduates' daily tasks. Therefore, a more global approach to integrating professional competencies in the curriculum can be implemented when professional competencies are distributed across different technical subjects, instead of having dedicated courses. In this case, students acquire professional competencies in a STEM environment, creating a relationship between these competencies and professional activities. 
Several recent examples of the integration of one or more professional competencies into existing technical courses can be found in the literature. Most of them follow the IEEE/ACM Computing Curricula recommendations (ACM, 2008), which propose the use of projects or case studies to ensure that students can successfully apply the knowledge they have acquired. With this approach, they manage to intertwine content and competencies. For example, Aliakbarian (2014) integrates guided independent learning (Leuven, 2005) into a project-based course (a telecommunication system design project). Although they focus on autonomous learning, they also tackle the development of other professional competencies such as teamwork, progress reporting, problem solving and communication skills. The main distinctive features are the structure of teams (macro-groups, micro-groups and individuals) as well as the changing levels of guidance and supervision from the beginning of the semester until the testing phase at the end. Ackay (2010) uses a constructivist student-centered approach for improving the understanding of technical concepts, while developing competencies such as creativity, positive attitude and innovation. The effects are evaluated by means of a comparison with students following the same semester course based on a traditional approach. Arbelaitz (2015) presents the use of active learning methodologies in a basic computer architecture course, which also addresses autonomous learning (and indirectly other professional competencies). These methodologies include project-based learning (PBL), as well as collaborative learning (Jigsaw-based learning). Students work autonomously in several tutored sessions where the lecturer tries not to instantly answer the questions, but to promote reflection within the group to answer them. The approach is evaluated by measuring students' dedication time, students' marks (including both teachers' and peers' evaluations), and students' level of satisfaction. Data for three academic years are provided, showing an improvement in both, students' academic performance and satisfaction. A smart home test bed, based on the pedagogical model of PBL for undergraduate education, is presented by $\mathrm{Hu}$ (2015). It provides a platform for students to develop their creativity in electrical and computer engineering design, combining autonomous learning and sustainability skills. O'Connell (2015) describes the beneficial changes observed in the implementation of team-based learning (TBL) in circuit theory since 2010. TBL is a particular form of the so called flipped classroom (or inverted classroom) strategy where, before attending the class, students must look for new materials in a variety of sources, including textbooks, web tutorials, papers and lecture notes. Thus, apart from teamwork, autonomous learning and information literacy skills are also tackled, as well as communications skills. 
Similarly, other proposals integrate TBL and the development of various professional competencies. A robotics competition (Cybertech) is used by Hernando (2011) as an opportunity to span theory, practical laboratory lessons, seminars and tutoring, integrating technical aspects but also teamwork skills, oral presentations, budget management, and entrepreneurship. They consider it as the flagship of innovation in education at the Universidad Politécnica de Madrid. Mahan (2000) integrates communication skills (writing) into a first-year course on electrical engineering by establishing a collaboration with writing specialists from other departments. He suggests that this collaboration is crucial for successful practice since both technical content and writing deserve appropriate attention, which justifies the need for one lecturer per area. Once more, the assessment of the experience is an anonymous poll among students, with an overwhelmingly positive response. Quinn (2005) deals with sustainability and social commitment by integrating a three-hour ethics case study laboratory into a first-year course for electrical and computer engineering students. The authors first describe their approach in (Clancy, 2001), and enhance it in Quinn (2005) with the use of pre-surveys and post-surveys among students in order to assess their awareness of ethical issues. These results are provided for two terms. Finally, a method to develop teamwork skills is presented by Pimmely (2003). Existing group assignments are converted into a teamwork learning experience by adding a small amount of class time and instructor time to train, monitor and evaluate teams. The method uses cooperative learning methodologies, including peer evaluation as a critical component. As a result, the method allegedly leads not only to a better experience in teaming for students, but also to a higher level of technical achievement on the projects (students can tackle and complete more difficult tasks through working as a team). Multiple data are used for assessing the effectiveness of this approach, including weekly progress reports, peer-evaluation forms, an end-of-project survey, a portion of the end-of-semester course survey that focuses on the project, and students' grades on the project report.

Other approaches have been proposed in the literature to integrate competencies across the curriculum. For example, Tribus (2005) describes how to combine the quality management principles of Deming with the educational theories of Feuerstein and Bloom's taxonomy in order to design a system of engineering education (i.e., a set of components working together to achieve a defined goal). It also uses a "matrix of competencies", but differs considerably from the one proposed here in that it is aimed at one subject only, and it does not consider the curriculum as a whole. Finally, Appleton (2007) presents a guide for curriculum developers that proposes to include materials to develop general skills such as reasoning, 
problem-solving, and behavioral skills in addition to vocational skills. The approach is based on two theoretical models: Systematic Curriculum Instructional Design (Norton, 1997) and Understanding By Design (Wiggins, 1998), and four selected applied models.

\section{INSTITUTIONAL CONTEXT OF THIS WORK}

The proposal presented in this study has been designed and implemented according to the educational framework defined in our institution. Just to help the reader understand the general context of this work, some details are presented about the authors' institution, the Barcelona School of Informatics ${ }^{7}$ from Universitat Politècnica de Catalunya-BarcelonaTECH , with its specific set up professional competencies to be developed in the Bachelor Degree in Informatics Engineering ${ }^{8}$.

In order to meet standards of excellence, the authors' institution takes into consideration its position in some international academic rankings. In recent years, Barcelona School of Informatics has climbed positions in the most outstanding academic rankings, which are mainly based on research activity and academic results. Among others, Barcelona School of Informatics appears in the following five rankings:

- $\quad$ Academic Ranking of World Universities (ARWU - Shanghai ranking ${ }^{9}$ ). It sorts the world's top 200 universities in computer science, considering both academic quality and research indicators. This is one of the most prestigious rankings in the world and only three Spanish computer science schools are included. Barcelona School of Informatics ranks 21st in Europe and 3rd in Spain (see Table 1).

- QS World University Rankings ${ }^{10}$ by Subject. This ranking is intended to compare institutions in terms of their reputation and their scientific impact. Barcelona School of Informatics ranks 28th in Europe and 1st in Spain (see Table 1).

- $\quad$ Best Global Universities Ranking (US News) ${ }^{11}$. This ranking orders institutions from the analysis of 12 quantitative research and reputation indicators. Barcelona School of Informatics ranks $10^{\text {th }}$ in Europe and $1^{\text {st }}$ in Spain (see Table 1).

- National Taiwan University Ranking. Performance Ranking of Scientific Papers ${ }^{12}$. This ranking is designed to compare quantitative and qualitative aspects, taking into account institutions' efforts in the

\footnotetext{
${ }^{7}$ https://www.fib.upc.edu/en. Last accessed March 2018.

${ }^{8}$ https://www.fib.upc.edu/en/studies/bachelors-degrees/bachelor-degree-informatics-engineering/curriculum/competences. Last accessed March 2018.

${ }^{9} \mathrm{http} / / /$ www.shanghairanking.com/. Last accessed March 2018.

${ }^{10} \mathrm{http}: / /$ www.topuniversities.com/subject-rankings. Last accessed March 2018.

${ }^{11}$ http://www.usnews.com/education/best-global-universities. Last accessed March 2018.
} 
long and short terms. Barcelona School of Informatics ranks 13rd in Europe and 2nd in Spain (see Table $1)$.

- $\quad$ Rankings I-UGR of Spanish Universities ${ }^{13}$. This ranking is based on research published in international journals with the highest impact and visibility. Barcelona School of Informatics ranks 4th.

\begin{tabular}{cllll}
\hline ranking & scope & rank & total & Quartile \\
\hline ARWU 2015 & World & $101-150$ & 200 & Q3 \\
\cline { 2 - 5 } & Europe & 21 & 61 & Q2 \\
\cline { 2 - 5 } & Spain & 3 & 9 & Q2 \\
\hline \multirow{2}{*}{ QS WURS 2016 } & World & $51-100$ & 503 & Q1 \\
\cline { 2 - 5 } & Europe & 28 & 211 & Q1 \\
\cline { 2 - 5 } 2016 & Spain & 1 & 8 & Q1 \\
& World & 37 & 200 & Q1 \\
\cline { 2 - 5 } & Europe & 10 & 63 & Q1 \\
\cline { 2 - 5 } & Spain & 1 & 7 & Q1 \\
\hline NTUR 2016 & World & 79 & 107 & Q1 \\
\cline { 2 - 5 } & Europe & 13 & 13 & Q1 \\
\cline { 2 - 5 } & Spain & 2 & 42 & \\
\hline I-UGR (Spanish) & Spain & 4 &
\end{tabular}

Table 1 Position of Barcelona School of Informatics - Universitat Politècnica de Catalunya-BarcelonaTECH in different rankings

Table 1 summarizes the position of Barcelona School of Informatics in these rankings for the different scopes ${ }^{14}$. As shown in the table, Barcelona School of Informatics is in relevant positions in all of them. In order to design a model to develop professional competencies, one of authors' initial considerations was the framework set by Universitat Politècnica de Catalunya-BarcelonaTECH, which included a list of seven professional competencies that must be incorporated in all university degrees. The university also issued a guide with recommendations on how to integrate these professional competencies into degree programs. The recommended procedure is based on the three-level hierarchical model described above. However, each department and school can adapt this model to integrate these domain levels most appropriately in their curricula.

Barcelona School of Informatics has defined nine professional competencies to be integrated in the Bachelor Degree in Informatics Engineering (the seven competencies selected by Universitat Politècnica

\footnotetext{
${ }^{12}$ http://nturanking.lis.ntu.edu.tw/Default.aspx. Last accessed March 2018.

${ }^{13} \mathrm{https}$ ///www.upc.edu/ranquings/en/upc-at-national-rankings/rankings/i-ugr. Last accessed March 2018.

${ }^{14}$ Although Universitat Politècnica de Catalunya-BarcelonaTECH has two schools teaching the Bachelor Degree in Informatics

Engineering, the Barcelona School of Informatics provides more than $90 \%$ of graduates and scientific production, so authors assume the results from Table 1 are mainly based on Barcelona School of Informatics statistics.
} 
de Catalunya-BarcelonaTECH plus two specifically selected by Barcelona School of Informatics: Entrepreneurship and Innovation, Sustainability and Social Commitment, Foreign Language Skills, Effective Oral and Written Communication, Teamwork, Information Literacy, Autonomous Learning, Appropriate Attitude towards Work, and Reasoning.

Barcelona School of Informatics has also developed a procedure to integrate these competencies in the Degree. The procedure includes assigning a coordinator to each competency, as well as setting up a team with these coordinators to work globally on the integration of the professional competencies. Working in this group, and sharing the experience of all coordinators, is helping to implement a global approach to the integration of professional competencies and make improvements for better practice.

\section{COMPETENCY MAPS: A MODEL TO INTEGRATE PROFESSIONAL}

\section{COMPETENCIES}

Taking into consideration the university proposal (based on a three-level hierarchical approach) and the defined competencies for the Bachelor Degree in Informatics Engineering, the authors devised a strategy to integrate the nine professional competencies, and started its implementation. After two-year experience and the received feedback, the authors decided to revise some aspects since some difficulties were identified. The authors had defined the contents of each professional competency into three domain levels, which resulted in general learning outcomes that were too extensive to be included in one subject. These learning outcomes were also difficult to split to be assigned to more than one subject. Thus, the initial approach had to be reviewed.

\section{A. The competency map}

The main revision involved the contents of the different professional competencies, which led authors to design a map of learning outcomes defined for each domain level. These learning outcomes were redefined to make them more specific and more flexible for a more appropriate integration. As an example, we found that lecturers responsible for developing professional competencies in their courses did not often have an appropriate, accurate list of learning outcomes to be achieved. For example, in the case of the Effective oral and written communication competency, initially they only planned to evaluate the skills involved in two communicative tasks: writing reports and preparing a project defense. They did not even have a plan to train students previously. 
In order to help lecturers become aware of specific learning outcomes and contents associated to the assigned professional competency it was decided that, for the nine professional competencies, a list of competency units (aspects or dimensions) could be set up, and learning outcomes at three domain levels could be defined for each competency unit. For instance, in the Effective oral and written communication competence, eight competency units were defined: using visuals, synthesizing skills, elaboration of arguments, reasoning and conclusions, elaboration of examples and metaphors, elaboration of reports, public defense, participation in debates and brainstorming activities, and interpersonal communication. Then, a set of expected learning outcomes was defined for each competency unit and domain level. This approach resulted in a competency map in which specific learning outcomes were clearly defined for the corresponding competency units and domain levels (as shown the example in Fig. 5 for a subset of competency contents).

The learning outcomes set for each domain level in the map may not coincide exactly with the first three domain levels in Bloom's taxonomy but, in most cases, this is the basis for grading them. In general, level 1 could correspond to the "knowledge" level, the expected learning outcomes in level 2 could be associated to the "comprehension" level, and level 3 would be concerned with the "application" level. In order to illustrate this grading, Fig. 5 shows how learning outcomes and domain levels have been defined for two competency units in the case of the Effective oral and written communication competency. For example, we can see that, in order to put in practice the use of visuals in an STEM context, the first domain level focuses on getting to know the available visuals and their use. Later, domain level 2 is devoted to understanding how visuals are applied as the identification of relevant/redundant information in a visual is practiced. Finally, in domain level 3, application is required as appropriate visuals are selected and designed for a specific case.

\begin{tabular}{|c|c|c|c|}
\hline \multicolumn{4}{|c|}{ EFFECTIVE ORAL AND WRITTEN COMMUNICATION. COMPETENCY MAP } \\
\hline \multirow[b]{2}{*}{ Competency Units } & \multicolumn{3}{|c|}{ Learning Outcomes } \\
\hline & $\begin{array}{c}\text { DOMAIN LEVEL } 1 \\
\text { Knowledge }\end{array}$ & $\begin{array}{c}\text { DOMAIN LEVEL } 2 \\
\text { Comprehension }\end{array}$ & $\begin{array}{c}\text { DOMAIN LEVEL } 3 \\
\text { Application }\end{array}$ \\
\hline Using visuals & $\begin{array}{l}\text { Becoming aware of } \\
\text { visual types and }\end{array}$ & $\begin{array}{l}\text { Identifying the relevant } \\
\text { information in a given }\end{array}$ & $\begin{array}{l}\text { Selecting an appropriate } \\
\text { visual to represent and }\end{array}$ \\
\hline
\end{tabular}




\begin{tabular}{|c|c|c|c|}
\hline \multicolumn{4}{|c|}{ EFFECTIVE ORAL AND WRITTEN COMMUNICATION. COMPETENCY MAP } \\
\hline & $\begin{array}{l}\text { explaining their } \\
\text { common uses. }\end{array}$ & $\begin{array}{l}\text { visual. Recognizing } \\
\text { redundant detail and } \\
\text { suggesting } \\
\text { improvement. }\end{array}$ & $\begin{array}{l}\text { transmit a given set of } \\
\text { data according to genre, } \\
\text { purpose and audience. } \\
\text { Implementing it. }\end{array}$ \\
\hline Synthesizing skills & $\begin{array}{l}\text { Given a source (text, } \\
\text { conference, lesson, ...) } \\
\text { determining the most } \\
\text { relevant information / } \\
\text { the most important } \\
\text { ideas. }\end{array}$ & $\begin{array}{l}\text { Given a source and a } \\
\text { summary, making a } \\
\text { review of the summary: } \\
\text { length suitability, ideas } \\
\text { that have been omitted } \\
\text { or too highly rated, ... }\end{array}$ & $\begin{array}{l}\text { Preparing a summary } \\
\text { from a source, under } \\
\text { certain constraints } \\
\text { (time, space, } \\
\text { presentation method, } \\
\text {...). }\end{array}$ \\
\hline
\end{tabular}

Fig. 5. Effective oral and written communication competency: example of two competency units and domain levels description in terms of learning outcomes.

This model based on maps allows a flexible integration of intended learning outcomes into subjects. Learning outcomes are defined according to competency unit and domain level, so that they can be assigned to subjects most appropriately. For example, one of the subjects in the first year could be assigned only one of the learning outcomes for level 1, while another subject could include another learning outcome at the same level, or even some learning outcomes belonging to different domain levels/competency units. Students are thus more aware of the specific learning outcomes they have to attain, which can promote reflection on the progress they need to make to develop professional competencies (Cajander, 2011).

This model also allows to combine and integrate specific learning outcomes and competency units. This is possible when various competency units and learning outcomes are related or fit appropriately in the contents of a course. This is shown in Fig. 6, where the dark boxes represent how some learning outcomes of several competency units have been assigned to one specific subject. This model becomes flexible enough to integrate learning outcomes at one or more domain levels into the same subject, to assign learning outcomes of various competency units at the same level, and even to avoid assigning learning 
outcomes of some competency units if convenient. This flexibility is allowed for domain-specific competencies, and it seems to be also appropriate for professional competencies.

\begin{tabular}{|c|c|c|c|}
\hline $\begin{array}{c}\text { Professional } \\
\text { Competency } \mathbf{X}\end{array}$ & $\begin{array}{c}\text { Learning outomes } \\
\text { of level 1 }\end{array}$ & $\begin{array}{c}\text { Learning outomes } \\
\text { of level 2 }\end{array}$ & $\begin{array}{c}\text { Learning outomes } \\
\text { of level 3 }\end{array}$ \\
\hline Competency unit 1 & & & \\
\hline Competency unit 2 & & & \\
\hline Competency unit 3 & & & \\
\hline Competency unit 4 & & & \\
\hline Competency unit 5 & & & \\
\hline Competency unit 6 & & & \\
\hline Competency unit 7 & & & \\
\hline Competency unit 8 & & & \\
\hline
\end{tabular}

Fig. 6. Competency map with competency units and learning outcomes assigned to one subject (shaded cells).

Furthermore, competency maps offer a tool to control competency itineraries. As shown in Fig. 7, the subjects to which competency units, domain levels and learning outcomes are assigned for a competency may be visualized. In this example, the learning outcomes represented in Fig. 6 are assigned to subject S1. It can also be seen how other competency units and domain levels are assigned to other subjects (S2-S5).

\begin{tabular}{|c|c|c|c|}
\hline $\begin{array}{c}\text { Professional } \\
\text { Competency X }\end{array}$ & $\begin{array}{c}\text { Learning outomes } \\
\text { of level 1 }\end{array}$ & $\begin{array}{c}\text { Learning outomes } \\
\text { of level 2 }\end{array}$ & $\begin{array}{c}\text { Learning outomes } \\
\text { of level 3 }\end{array}$ \\
\hline Competency unit 1 & s 1 & s 2 & s 2 \\
\hline Competency unit 2 & s 1 & s 1, S 3 & s 1 \\
\hline Competency unit 3 & s 1 & s 1 & s 1 \\
\hline Competency unit 4 & s 2 & s 3 & s 4 4 \\
\hline Competency unit 5 & s 3 & s 1, s 2 & s 1 \\
\hline Competency unit 6 & s 2 & s 3 & s 3, s 5 \\
\hline Competency unit 7 & s 1 & s 5 & s 5 \\
\hline Competency unit 8 & s 3 & & \\
\hline
\end{tabular}

Fig. 7. Itinerary of a competency in the curriculum.

These itineraries help curriculum designers to adjust this integration most conveniently when necessary.

As displayed in Fig. 7, competency maps prove to be very useful to check how learning outcomes are assigned throughout the degree, how some may be recurrent and how some could not be covered. Indeed, the specific curriculum has to define the domain levels for each professional competency and, accordingly, the map could show some blank cells. This may occur when curriculum design states that a specific competency unit and domain level is not to be developed in a particular degree. For example, 
some high-level learning outcomes could be more appropriately attained in master programs, whereas some low-level learning outcomes could be left out of the map. To illustrate this idea in our center, and following the example of the two competency units shown in Fig. 5, level 1 and 2 of using visuals and level 1 of synthesizing skills were assigned to the Physics subject (first year, first semester), while level 3 of using visuals was assigned to the Statistics subject (second year, first semester).

\section{B. The global competency map}

The global competency map is a matrix that combines the maps of all professional competencies in order to provide a picture of their development. Again, this useful tool provides further information for all designers and coordinators to optimize workload. First, all competency units need to be defined, as well as the corresponding three-level learning outcomes, to identify partial or complete redundancies across competencies. Then, if overlapping competency units are identified, designers can decide whether it is necessary to avoid those redundancies or not. In fact, after constructing the first global map, authors realized that some professional competencies shared some competency units. Therefore, they decided to carry out a second iteration to simplify the map where necessary. Fig. 8 shows how this is made apparent in the global map, and how the map can help to start revisions as necessary (domain levels have been omitted to simplify the figure).

\begin{tabular}{|c|c|c|c|c|}
\hline & $\begin{array}{c}\text { Professional } \\
\text { Competency } \\
1\end{array}$ & $\begin{array}{c}\text { Professional } \\
\text { Competency } \\
2 \\
\end{array}$ & $\begin{array}{c}\text { Professional } \\
\text { Competency } \\
3 \\
\end{array}$ & $\begin{array}{c}\text { Professional } \\
\text { Competency } \\
4 \\
\end{array}$ \\
\hline Competency unit 1 & $x$ & & & $\mathrm{x}$ \\
\hline Competency unit 2 & $x$ & & & \\
\hline Competency unit 3 & & $x$ & & \\
\hline Competency unit 4 & & $\mathbf{x}$ & $x$ & \\
\hline Competency unit 5 & & & $x$ & \\
\hline Competency unit 6 & & & $x$ & \\
\hline Competency unit 7 & & & $x$ & \\
\hline Competency unit 8 & $x$ & & & $x$ \\
\hline Competency unit 9 & & & & $x$ \\
\hline Competency unit 10 & & & & $x$ \\
\hline
\end{tabular}

Fig. 8. Map of competency units and competencies in the curriculum.

Some of the coincidences identified in the global map were actually handled in different ways. In some cases, authors decided that it was necessary to simplify the map and fuse competency unit. This is the case of coincidence found between communication and teamwork. Authors found that a competency unit 
named "interpersonal communication" was listed in the maps of both professional competencies, with shared learning outcomes.

However, authors found it appropriate to maintain learning outcomes and some overlapping practice in other cases. For example, some of the learning outcomes of effective oral and written communication show some coincidence with those defined for foreign language skills, since both share some learning outcomes to develop writing skills and oral communication. Nevertheless, authors understand that learning outcomes need to be maintained in each competency since they are approached differently. In addition, it is also true that recurrent practice proves to be effective in the development of competence and ability in general, which may reinforce authors' decision. Another example where authors did not find it convenient to fuse learning outcomes was the case of coincidence between teamwork and entrepreneurship and innovation. They share a competency unit named "decision making and problem solving”. In this case, in spite of competency unit overlapping, the learning outcomes defined for teamwork were more specific, and so authors decided that it would be effective to maintain them in both professional competencies.

\begin{tabular}{|l|l|l|l|l|l|l|l|l|l|l|l|l|}
\hline & \multicolumn{2}{c}{$\begin{array}{c}\text { Professional } \\
\text { Competency 1 }\end{array}$} & \multicolumn{2}{c|}{$\begin{array}{c}\text { Professional } \\
\text { Competency 2 }\end{array}$} & \multicolumn{3}{c|}{$\begin{array}{c}\text { Professional } \\
\text { Competency 3 }\end{array}$} & \multicolumn{3}{c|}{$\begin{array}{c}\text { Professional } \\
\text { Competency 4 }\end{array}$} \\
\hline & L1 & L2 & L3 & L1 & L2 & L3 & L1 & L2 & L3 & L1 & L2 & L3 \\
\hline Competency unit 1 & & & & & & & & & & & & \\
\hline Competency unit 2 & & & & & & & & & & & & \\
\hline Competency unit 3 & & & & & & & & & & & & \\
\hline Competency unit 4 & & & & & & & & & & & & \\
\hline Competency unit 5 & & & & & & & & & & & & \\
\hline Competency unit 6 & & & & & & & & & & & & \\
\hline Competency unit 7 & & & & & & & & & & & & \\
\hline Competency unit 8 & & & & & & & & & & & & \\
\hline Competency unit 9 & & & & & & & & & & & & \\
\hline Competency unit 10 & & & & & & & & & & & & \\
\hline
\end{tabular}

Fig. 9. Global competency map.

All these decisions can be shown in the global competency map, where the results of the revisions are specified. As shown in Fig. 9, the map displays the three-domain level for each competency unit and competency. According to their descriptors, those coincidences can be identified to take decisions, as changes can be shown in the map. It is possible to keep record of all this procedure for curriculum design, making the map a very useful tool for present and future work. 


\section{Implementation procedures}

As described above, in order to shape the integration of professional competencies, it is necessary to coordinate implementation procedures to help participants (course coordinators, lecturers and learners) make the most of the experience. At Barcelona School of Informatics, a coordinator was appointed for each professional competency under the supervision of a general team coordinator. Each competency coordinator was in charge of defining learning outcomes and competency units, and assigning specific learning outcomes to subjects according to a competency itinerary previously defined by the curriculum. Work was started with the corresponding course coordinators, and competency coordinators met regularly to report on the progress made, to share implementation strategies and to take decisions about common procedures.

After defining contents for each professional competency, authors started a procedure to integrate all competencies in the degree subjects. Competency coordinators organized meetings with course coordinators in order to discuss how competency learning outcomes could best fit in their course syllabuses. This included discussing learning outcomes in the competency map, designing effective practice activities, and taking decisions about assessment methods. These first contacts showed that, in general, course coordinators and lecturers needed some guidance to integrate the professional competencies assigned. More specifically, for some professional competencies and subjects, this integration could be planned quite naturally in the course syllabus with some guidance, whereas in other cases a specific professional competency was very difficult to implement because it did not fit easily into course contents. In the latter cases, authors decided to reassign a more appropriate competency to the subject, with the corresponding adjustments in other subjects to keep a balanced map.

After receiving the first feedback, the authors decided that it was necessary to make some general adjustments as convenient. Firstly, professional competencies were reassigned in a few cases so that course coordinators felt comfortable with integrating the corresponding learning outcomes. In general, most subjects were assigned to develop and evaluate one or two professional competencies, and up to three in the case of subjects based on PBL methodology. Secondly, after coordinators shared the feedback received, it was possible to design a global strategy for the implementation of all competencies. This included planning effective iteration with the corresponding course coordinators for a finely tuned implementation of the competency map. 
The outcome of all this process is the proposed model to integrate professional competencies in the Bachelor Degree in Informatics Engineering, introduced at Barcelona School of Informatics in September 2010. Authors have defined nine competency maps and a global competency map that constitute a useful tool for curriculum design. These maps allow to implement a procedure to integrate professional competencies which is based on iteration and refined improvement.

\section{ANALYSIS OF RESULTS AND DISCUSSION}

The evaluation of the present model was based on the final design of a flexible, integrative competency map, and on the different information sources that can shed some light on its effectiveness. We assessed the correct design implementation of each competency map (research question 1), and observed the results of students' achievements throughout the degree. In addition, we surveyed the significance of the integration of professional competencies in the Bachelor's Degree in Informatics Engineering at Barcelona School of Informatics. Other evaluation data included the reports on students' achievement and progress, and some studies carried out by different institutions in the light of the opinions of students and employers. The following sections show some of them.

\section{A. Quantitative students' data}

This section addresses research question number 2: Do students improve their professional skills by using competency maps as a methodology?

In our model, a subject that integrates professional competencies must provide students' assessment results for each professional competency. Each subject assesses at least one professional competency. In some cases, it can assess two, and even three competencies in subjects based on PBL methodology. The final grade of a subject is rated between 0 and 10 and combines the assessment of both technical and professional competencies developed in the subject. However, each professional competency also gets a particular grade (rated A, B, C or $\mathrm{D}^{15}$ ). Although passing the subject depends only on the final grade, the separate professional competency grade indicates students' progress in a particular competency, and it is also a mechanism to highlight the importance given to professional competencies in the degree.

Students' competency assessment has been achieved through a broad set of activities and pedagogical approaches. Lecturers include case-studies, discussion, group work, workshops and projects for task

\footnotetext{
${ }^{15}$ The professional competency grades means: A competency acquired with excellence, B good, C sufficient, and D deficient acquisition of the competency. The grade can be NA (not applicable) in some cases (for instance, if the student drop the subject).
} 
design, and they use a variety of methods like project based learning, cooperative learning, challengebased instruction, coaching, and formative and summative assessment. In general, assessment has been based on an accurate definition of competency learning outcomes and the use of rubrics to evaluate them. To this end, a reference manual based on the Tuning Project was used (Villa, 2008).

The quantitative students' data presented here summarize the grades of professional competencies obtained by students that presented their Final Year Project (FYP) during 2013, 2014, 2015 and 2016. The data include the grade of the 384 FYP (each FYP assesses seven professional competencies and gives a specific grade for each competency) and a total of 18695 students' grades from 96 different subjects in the curriculum.

Students' grade distribution during the four courses (from 2013 to 2016) for all professional competencies in the curriculum is presented in Fig. 10. As can be seen, more than $80 \%$ of evaluated students have reached the higher scores (A or B), confirming these results as highly satisfactory.

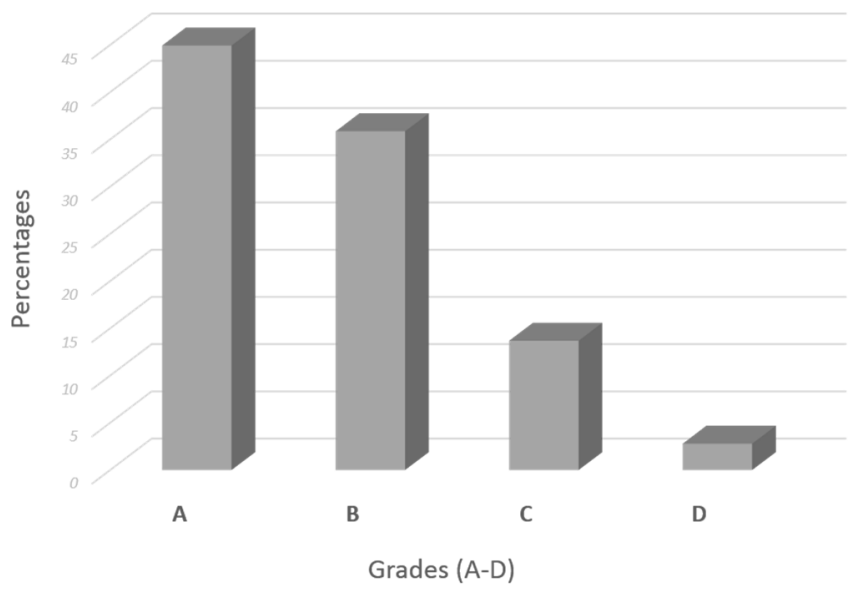

Fig. 10. Students' grades distribution from 2013 to 2016

\section{B. Qualitative students' data}

This section addresses research question 3: Are students satisfied with the progress made in professional competencies? Do they consider professional competencies important?

The Barcelona School of Informatics has designed a specific questionnaire to assess the degree of importance and satisfaction among students with respect to their own professional competencies. This 
survey has been conducted every year among graduating students since 2013 , the first class using the methodology proposed in this work.

All graduating students have been asked to answer some questions related to the importance they give to professional competencies, and how they have acquired them during their studies. All answers are based on a rating scale from 1 (strongly disagree) to 4 (strongly agree). Four years have been evaluated since the new degree started to be implemented, from 2013 to 2016.

Fig. 11 shows the evaluation of the graduating students in July 2013 based on the following directions: "Assess the importance of each of the following competencies in the engineering professions". These students were the first class completing their engineering degree with the methodology presented in this work. As the figure shows, more than $83 \%$ of students clearly feel that professional competencies are important for the development of their professional activity (agree or strong agree), whereas only $16 \%$ think they are not relevant (disagree or strong disagree).

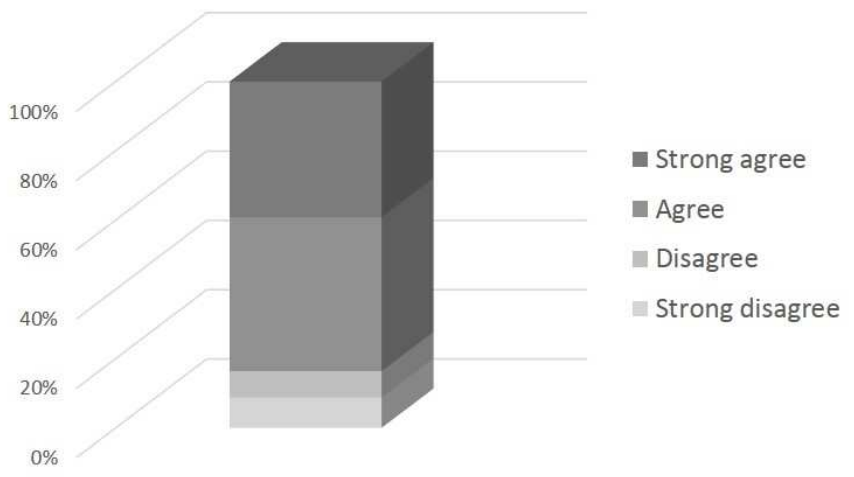

Fig. 11. Competency assessment average score (first class, 2013).

It can be observed that this perception of the importance of competencies is strengthened over time, as authors' teaching and learning methodologies are maturing. The evolution of student's opinion through the periods evaluated can be seen in Fig. 12. If $83 \%$ of the students from the first class thought that competencies were important, this figure grew up to $96 \%$ in 2016 . For each year, the number of students who answered the survey is presented in brackets. The first courses have fewer students because, since the degree was very recent, the number of students who finished was lower. 


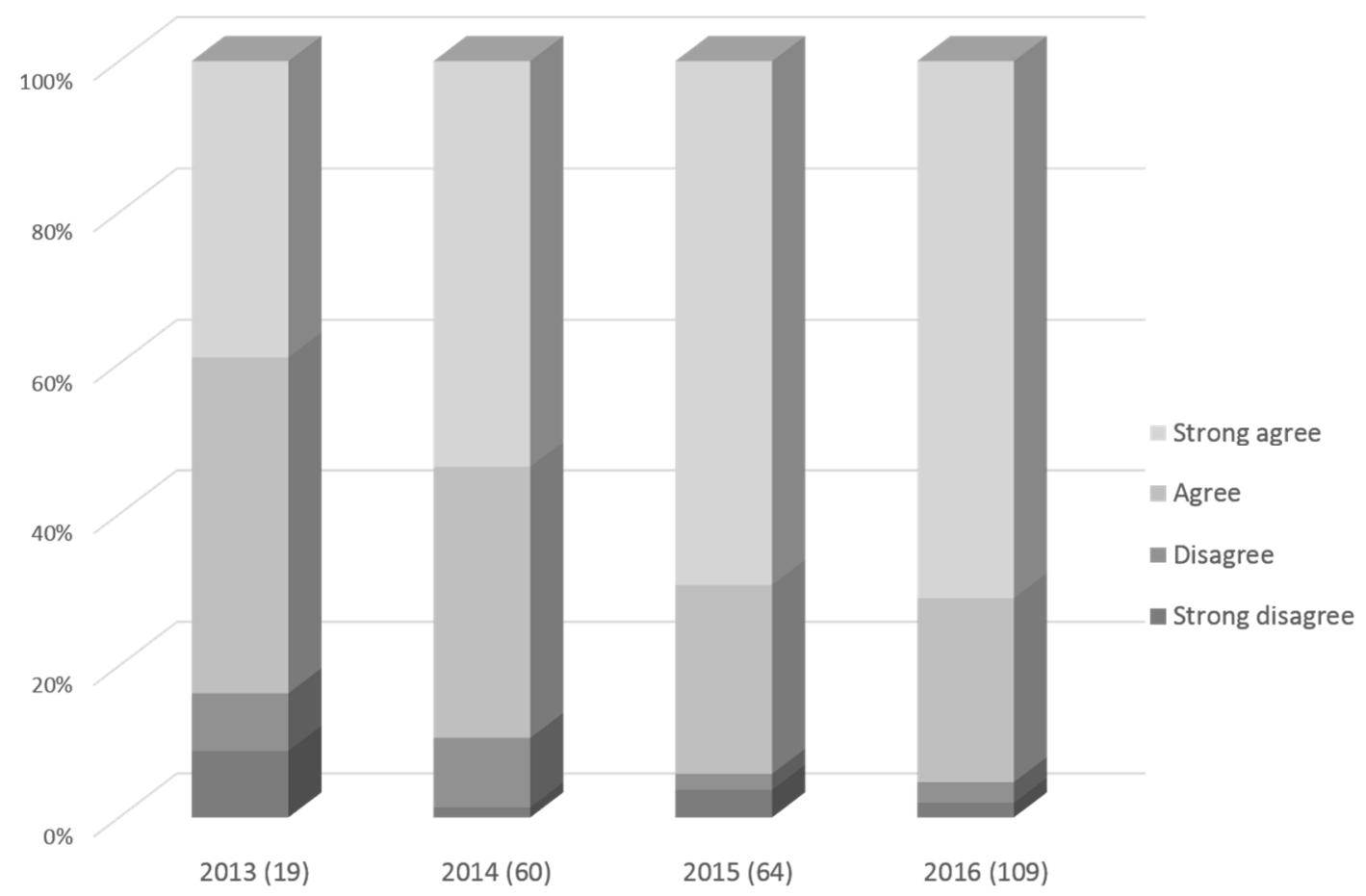

Fig. 12. Evolution of assessment average score through periods evaluated.

\section{Qualitative employers' opinion}

In sections $\mathrm{C}, \mathrm{D}$ and $\mathrm{E}$ below, data analyzed to address research question 4: What are employers' and international evaluation agencies' views on the results obtained by graduates who have been trained with competency maps?

As presented in the introduction, employers' surveys (AQU, 2014) show that professional competencies are more highly valued than technical ones, but they also suggest that some improvements are necessary in the development of students' professional competencies. Employers' opinions indeed shed light on the effectiveness of the method described in the present work.

Firstly, the Everis Foundation has recently elaborated the 1st University-Enterprise ranking ${ }^{16}$, including a survey among Spanish companies on the employability of graduates from 2011 to 2015. It is based on information provided by 2,000 employers from companies (in Spain) with more than 10 workers, over 21,700 young professionals from 95 degrees and 72 universities. The study considered eight competencies: analysis and problem solving, communication and interpersonal skills, teamwork, ability to work in multicultural and multidisciplinary environments, ability to learn and adapt to change, results

\footnotetext{
${ }^{16}$ https://www.fundacioneveris.com/ranking-2017. Last accessed March 2018.
} 
orientation, honesty and ethical commitment, and technical knowledge of the profession. "Technical knowledge" is the only domain-specific competency. The study includes all fields of knowledge, so this competency is assumed to be different for every profession. Although universities place most effort and emphasis on "technical knowledge", it appears as the least valued by employers.

Results show that, in STEM disciplines, the most valued school is Barcelona School of Informatics (1st in ranking). This fact corroborates that Barcelona School of Informatics graduates meet the needs of the labor market. According to the study, Barcelona School of Informatics graduates are excellent in honesty and ethical commitment, interpersonal and communication skills and ability to work in multicultural and multidisciplinary environments. The study also concludes that the competencies most valued by employers do not exactly match those being more common in university programs. Companies attach more importance to honesty and ethical commitment, learning ability and teamwork, whereas universities emphasize technical competencies, ability to work in multicultural and multidisciplinary environments and results orientation. Curriculum designers at Barcelona School of Informatics are aware of this problem, and have thus designed an informatics-engineering curriculum that aims at fostering the professional competencies most valued by employers.

Another report involving employers" opinions is the "Seminar on good practices in competencies assessment ${ }^{\star 17}$, held in Barcelona in November 2015. The seminar ${ }^{18}$ was organized by the Department of Didactics from Universitat de Barcelona. It presented the results and significance of assessing the development of competencies at tertiary level (Cano, 2012), a project supported by the Spanish Ministry of Economy and Competitiveness from January 2013 to December 2015. The data of the study came from closed questionnaires among students and teachers, discussion groups with students and teachers, and interviews with directors of studies and employers. Three universities were evaluated: Universitat de les Illes Balears, Universitat Oberta de Catalunya and Universitat Politècnica de Catalunya-BarcelonaTECH. According to these studies, it can be concluded that only Barcelona School of Informatics has an integral design of professional competencies in the curriculum. In other degree programs, teachers act individually and do not get any support. In some cases, a given professional competency is assigned to a subject but it is not treated in depth and/or there is no procedure to evaluate it. In general, there is no coordinated action

\footnotetext{
${ }^{17} \mathrm{http} / / / \mathrm{vseminaridebonespractiques.weebly.com/programa.html.} \mathrm{Last} \mathrm{accessed} \mathrm{March} 2018$.

${ }^{18} \mathrm{http}: / / \mathrm{vseminaridebonespractiques.weebly.com/presentacions.html.} \mathrm{Last} \mathrm{accessed} \mathrm{March} 2018$.
} 
to assign and develop professional competencies. Consequently, course coordinators and teachers report that they need help and guidance to tackle professional competencies appropriately.

\section{National and international accreditation}

Finally, the Bachelor's Degree in Informatics Engineering was evaluated during 2016 by national and international agencies such as $\mathrm{AQU}^{19}$ or $\mathrm{EQUANIE}^{20}$. Both of them have emphasized the integration of professional competencies in the curriculum. AQU granted the degree with national accreditation and quality mention. With respect to graduates' labor insertion, the AQU report emphasizes that Barcelona School of Informatics graduates are valued very positively by employers, mainly by their technological knowledge and level of autonomy (one of the professional competencies). AQU also highlights that using tools for the participation of representatives of the labor market in the definition of competencies is a good practice.

EQUANIE, in turn, has awarded the EURO-INF seal, a certificate awarded to a university for a bachelor or master degree programs in Informatics. The program is evaluated by using a set of defined standards according to the principles of quality, relevance, transparency, recognition and mobility covered by the EHEA. The EURO-INF seal is internationally recognized and allows to identify high quality Informatics programs in Europe. The committee highlights the following issues: "In terms of transversal competencies for the Bachelor and Master programs under review the peers confirmed that each module has at least one general competence assigned which has to be submitted and assessed by the respective professor. In order to assure that transversal competencies as well as personal/professional skills are delivered the school has set up coordinators who interact with the respective professor for each subject. The employers argued during the discussion that students have excellent technical skills and the ability for independent learning which is highly welcomed. However, they still see room for improvement when it comes to social skills. The peers welcomed the implemented monitoring process by the Barcelona School of Informatics and encouraged the school to further develop the transversal and professional skills of their students".

\section{E. Catalan Government survey among recent graduates}

\footnotetext{
${ }^{19}$ http://www.aqu.cat/index_en.html. Last accessed March 2018.

${ }^{20}$ http://www.eqanie.eu. Last accessed March 2018.
} 
The impact of technical and professional competencies on students' employability can be appropriately assessed once they have accessed the labor market. They can be asked to evaluate which competencies seem to be most useful and in which they were better trained. Since 2001, on a triennial basis, the Catalan University Quality Assurance Agency (AQU) and Catalan universities have performed an employment survey among graduates to enquire about professional insertion, and the degree of satisfaction regarding the training received ${ }^{21}$.

In 2014, all public and private universities in Catalonia participated in the 5th (and latest) edition of the survey. This is one of the most representative and important surveys in Europe, both for its scope and long trajectory (2001, 2005, 2008, 2011 and 2014 editions). On this occasion, 17,295 graduates were surveyed from a total reference population of 31,734. The number of Barcelona School of Informatics students participating in the survey changed over years, being 107 students out of 193 in 2008, 119 out of 330 in 2011 and 85 out of 174 in 2014. This variability in both the universe and sample is not relevant when comparing means as in the figures below.

The results of graduates' assessment of technical and professional competencies are presented by academic degree and can be extracted for particular universities. In order to present students' satisfaction with received professional competencies training, the last three polls (corresponding to 2008, 2011 and 2014) have been selected. Since the new curriculum described in this work was introduced in 2010, with the first class graduated in 2013, the results from the 2014 poll are considered and are compared against the previous ones. This results correspond to students' assessment of the accomplished training level for each professional competency in a range from 1 to 7 . In the same survey, students were also asked about the perceived usefulness of these competencies to find a job. The questions were:

- What do you think about the training you received at university?

- Is the level of training received at university useful for work?

As shown in Fig. 13 and Fig. 14, in general, the ratings that students assigned to their training increased in 2014 with respect to previous evaluations. Results also show an increased awareness of the usefulness of such professional competencies, indicated by higher ratings.

\footnotetext{
${ }^{21}$ http://www.aqu.cat/uploads/insercio_laboral/enquesta2014/index.html. Last accessed March 2018.
} 


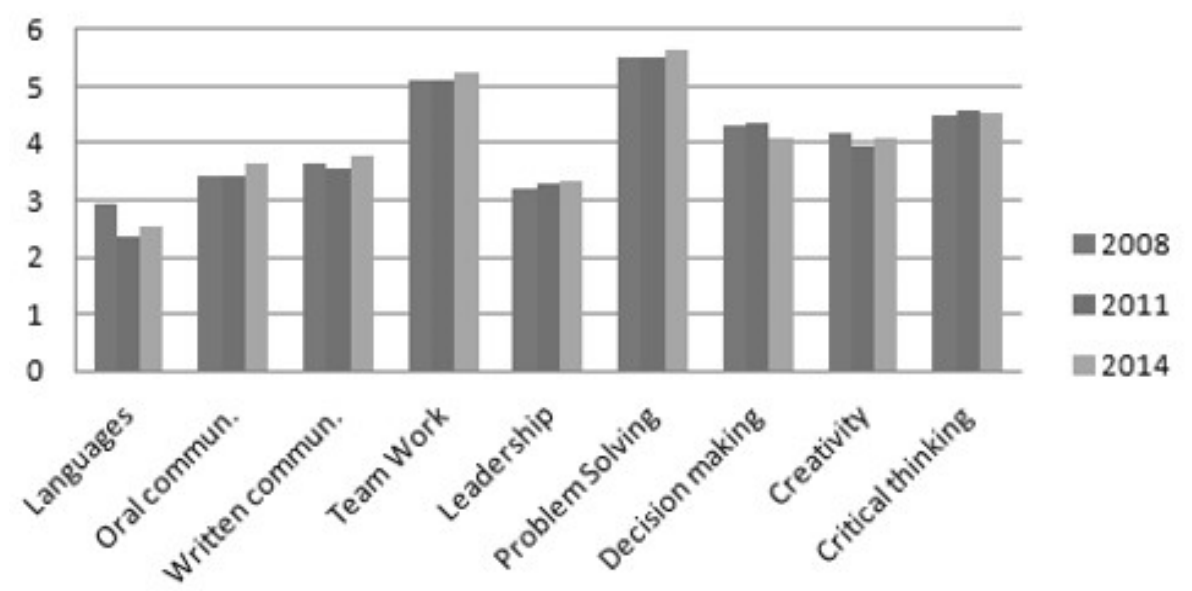

Fig. 13. Self-Evaluation of professional competency training.

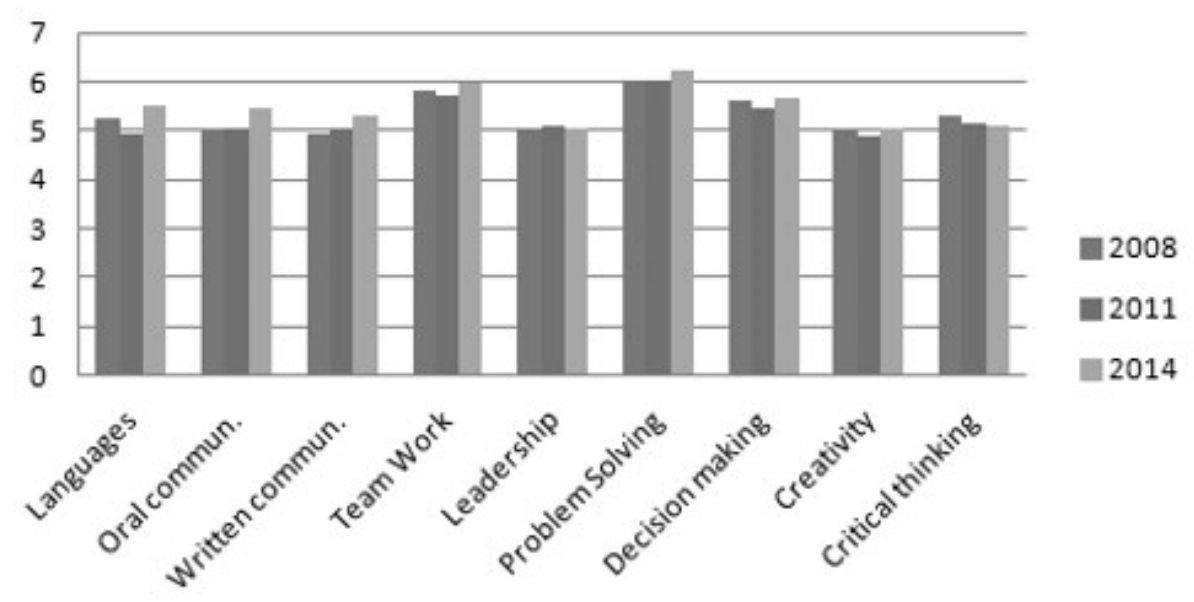

Fig. 14. Professional competency usefulness.

\section{F. Relationship between academic final grades and professional-competency grades}

Finally, this section looks into research question 5: Is there a relationship between the acquisition of technical competencies and the acquisition of professional competencies? Do students who get high academic final grades also get high grades in professional competencies and vice versa?

Both the final academic average grade and professional competency grades were extracted for each student to observe potential levels of association. They have been graphically represented to analyze significant facts about them. The final academic grade is displayed in the $\mathrm{X}$-axis (with a range from 1 to 10), versus the professional competency grade, which is represented in the Y-axis (with a range from 1 to 4). A density plot has been used in order to highlight the areas with higher overlapping points. As no relevant differences are observed between the graphs for each year and the global graph for any of the 
professional competencies, the analysis takes into account students' grades regardless of the year they finished their studies.

The grades of the nine professional competencies present three different patterns regarding their relationship to the final academic grade, as shown in Figure 15. Fig. 15(a) depicts the triangular distribution presented by the Teamwork competency. Sustainability and Social Commitment, Foreign Language Skills and Information Literacy present similar distributions. Fig. 15(b) shows the logarithmic pattern displayed by the Autonomous Learning competency. Entrepreneurship and Innovation, Effective Oral and Written Communication, and Appropriate Attitude towards Work present similar distributions. Finally, Fig. 15(c) shows the linear relationship presented by the "Reasoning" competency, the only one displaying this layout. None of the competencies grades follows a normal distribution, so all of them fail to accomplish normality according to the Shapiro-Wilk test (i.e. they show significant p-values).

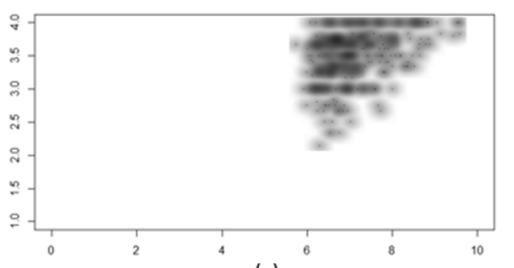

(a)

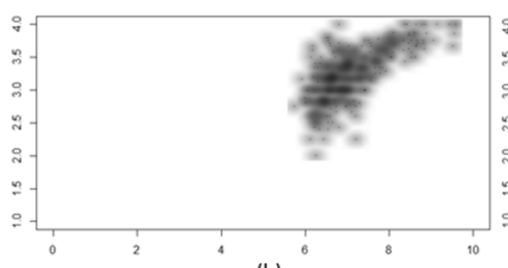

(b)

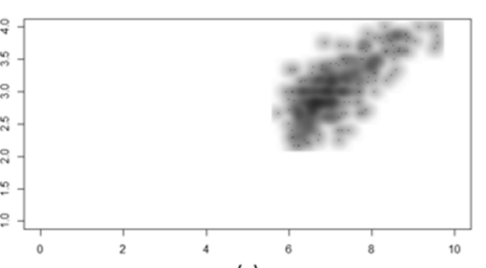

(c)

Fig. 15. Density plots representing the distribution types displayed by professional competencies grades versus final academic grade: (a) triangular, (b) logarithmic and (c) linear.

These three patterns represent that each competency grade has a lower bound that increases with the final academic grade. That is, there are no students with high final academic grade and low professional competency grades. Nevertheless, certain students whose academic performance is low might present more heterogeneous professional competency grades, some of them even quite high.

Fig. 16 shows the relationship between the average grade of all professional competencies for each student and his/her academic final grade. In this case, the distribution is clearly linear. On the contrary to the behavior observed for each individual professional competency, the average grade of all professional competencies follows a normal distribution, with a p-value in the Shapiro-Wilk normality test of 0.0207. 


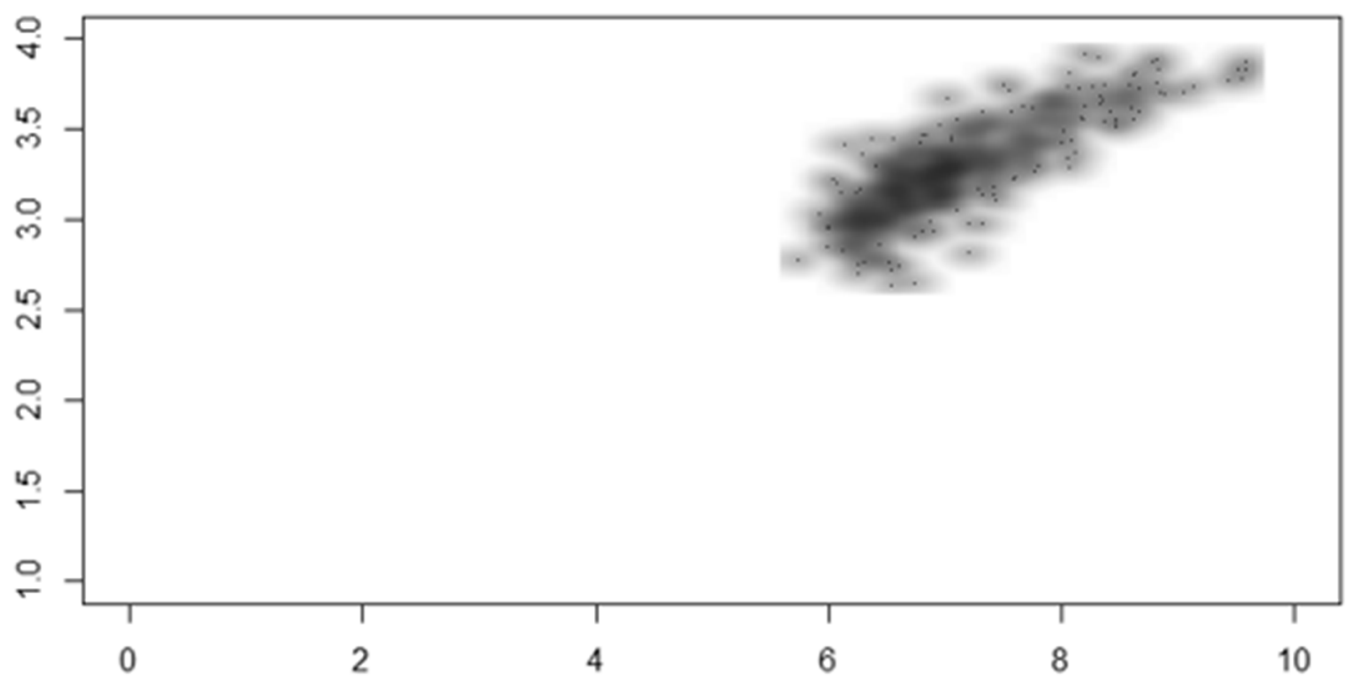

Fig. 16. Density plot representing the average professional competencies grade versus final academic grade for each student.

Table 2 shows the values of the Shapiro-Wilk statistics and their corresponding p-values, as well as the Spearman correlation between the final academic grade and each of the professional competencies, also with their corresponding p-values. The last row contains the information about the average grade for all the professional competencies. Since this average grade follows a normal distribution, we have also considered the Pearson correlation, which is 0.829 . In this case, the p-value is also significant $(<2.2 \mathrm{E}$ 16), confirming the strong level of association between the final academic grade and the average grade of all professional competencies.

\begin{tabular}{|c|c|c|c|c|}
\hline & \multicolumn{2}{|l|}{ Shapiro-Wilk normality Test } & \multicolumn{2}{l|}{ Spearman correlation test } \\
\hline Competency & Statistics & p-value & Spearman Corr & p-value \\
\hline Entrepreneurship and Innovation & 0,979 & $9,40 \mathrm{E}-06$ & 0,546 & $3,28 \mathrm{E}-34$ \\
\hline Sustainability and Social Commitment & 0,973 & $5,13 \mathrm{E}-07$ & 0,486 & $2,24 \mathrm{E}-26$ \\
\hline Foreign Language Skills & 0,96 & $2,51 \mathrm{E}-09$ & 0,44 & $2,12 \mathrm{E}-21$ \\
\hline $\begin{array}{c}\text { Effective Oral and Written } \\
\text { Communication }\end{array}$ & 0,957 & $9,97 \mathrm{E}-10$ & 0,444 & $7,75 \mathrm{E}-22$ \\
\hline Teamwork & 0,932 & $6,12 \mathrm{E}-13$ & 0,373 & $2,22 \mathrm{E}-15$ \\
\hline Information Literacy & 0,972 & $3,75 \mathrm{E}-07$ & 0,41 & $1,42 \mathrm{E}-18$ \\
\hline Autonomous Learning & 0,986 & $4,54 \mathrm{E}-04$ & 0,683 & $2,28 \mathrm{E}-59$ \\
\hline Appropriate Attitude towards Work & 0,982 & $4,44 \mathrm{E}-05$ & 0,593 & $1,95 \mathrm{E}-41$ \\
\hline Reasoning & 0,983 & $7,92 \mathrm{E}-05$ & 0,714 & $5,99 \mathrm{E}-67$ \\
\hline Average & 0,992 & $2,07 \mathrm{E}-02$ & 0,817 & $1,13 \mathrm{E}-102$ \\
\hline
\end{tabular}


Table 2. Shapiro-Wilk statistics values and Spearman correlation between the final academic grade and the grade of each professional competency plus their average, with their corresponding p-values.

Fig. 15 density plots show that the students with a high academic final grade never get low grades in none of the professional competencies. However, it also shows the existence of students with high qualification in some professional competencies regardless of their final academic grade.

As shown in Table 2, the level of association between each professional competency grade and the final academic grade is always significantly different from zero, although in most cases it is low, with the exception of "Autonomous Learning" and "Reasoning", whose Spearman correlation is respectively 68.3 and 71.4. Thus, in spite of the observed general trend that the higher the academic final grade, the higher the professional competencies grade, variability can be high in some cases. This relationship does not appear to be a trend in the case of low academic grades. Therefore, it can be assumed that the relationship is only significant in the following direction: high final academic grade implies high competency grade, whereas the opposite is not necessarily true.

Nevertheless, the average grade for all the professional competencies does indeed present a high level of association with the final academic grade $(81.7 \%)$. In this case, Pearson correlation is 0.829 , confirming quite a strong relationship between both grades. Therefore, for this global grade, we can make a twofold assumption: high academic final grade implies high competencies grade, and vice versa.

From these data, it can be inferred that the better the academic final grade of a student, the better the grade he/she will tend to have in all the competencies in general (thus obtaining a high average). On the other hand, the students with lower academic grades will present more variable scenarios with regards to competency performance. That is, they might have a low qualification in all the competencies, or only in some of them, and they may also be quite skilled in some particular professional competencies. The number of high graded professional competencies must necessarily increase with the academic final grade. Due to this, the average professional competencies grade for each student tends to correlate very well with his/her academic final grade, while it does not correlate so well with the grade of each individual competency.

\section{CONCLUSIONS}

Professional competencies are becoming more and more critical, particularly in STEM degrees, due to constant increases in multidisciplinarity and globalization. The need to include them in a STEM 
curriculum is currently a challenge for curriculum designers. Most universities have adjusted educational goals of undergraduate programs to address some of the professional competencies, including the use of PBL, co-curricular and extracurricular activities or by means of dedicated seminars or courses. The authors of this work believe that specific courses on professional competencies may help students to improve them. However, authors think that integrating professional competencies into the curriculum subjects is a more effective approach because it allows students to perceive these competencies as an important part of their future profession. The present work has described a proposal based on competency maps that allows to integrate professional competencies along the curriculum in a global approach.

Tools like the one presented in this work are required in order to develop a coherent and integral curriculum. The global competency map allows curriculum designers to assure that all students have the opportunity to acquire professional competencies at three domain levels, which appears to be more difficult to achieve in less systematic approaches. Furthermore, we highly recommend curriculum designers to develop competency maps for each competency because it helps STEM coordinators and lecturers (experts in technical competencies but not necessarily in professional competencies), to define expected learning outcomes and to design appropriate learning activities.

Our school curriculum has been designed on the basis of these competency maps (or more appropriate, the concept of maps was developed to design our curriculum). The four-year experience presented in this study shows that our model helps students generally achieve good results in the development of their professional skills. The organization design based on competency units and domain levels for each competency helps to grade competency development and acquisition effectively, and contributes to raising awareness of contents and practices. Thus, graduate students and their employers report that, in their opinion, professional competencies are acquired. Furthermore, the results shown that students with high academic grades have high competencies grades in general, which confirms that our integrative strategy provides the expected outcome. In the light of the positive results, this global design is suitable to help students develop professional competencies most appropriately.

\section{COMPLIANCE WITH ETHICAL STANDARDS}

Conflict of Interest:

- Author A declares that he/she has no conflict of interest.

- Author B declares that he/she has no conflict of interest. 
- Author C declares that he/she has no conflict of interest.

- Author D declares that he/she has no conflict of interest.

- Author E declares that he/she has no conflict of interest.

- Author F declares that he/she has no conflict of interest.

- Author G declares that he/she has no conflict of interest.

- Author H declares that he/she has no conflict of interest.

- Author I declares that he/she has no conflict of interest.

Ethical approval: All procedures performed in studies involving human participants were in accordance with the ethical standards of the institutional and/or national research committee and with the 1964 Helsinki declaration and its later amendments or comparable ethical standards.

Informed consent: "Informed consent was obtained from all individual participants included in the study."

This article does not contain any studies with animals performed by any of the authors.

\section{REFERENCES}

ABET (2017). Accreditation Criteria. Accreditation Board for Engineering and Technology, Inc.

Retrieved from http://www.abet.org/accreditation/accreditation-criteria/ (Last accessed March 2018).

ACM (2008). Computer science curriculum 2008: An interim revision of CS 2001. Report from the Interim Review Task Force. Association for Computing Machinery. IEEE Computer Society. Retrieved from https://www.acm.org/binaries/content/assets/education/curricularecommendations/computerscience2008.pdf (Last accessed March 2018).

Akcay, H. \& Yager, R.E. (2010). The Impact of a Science/Technology/Society Teaching Approach on Student Learning in Five Domains. Journal of Science Education and Technology, 19(6), 602-611.

Aliakbarian, H., Soh, P.J., Farsi, S., Hantao, X., Van Lil, E.H.E.M.J, Nauwelaers, B.K.J.C, Vandenbosch, G.A.E. \& Schreurs, D.M.M.-P. (2014). Implementation of a Project-Based Telecommunications Engineering Design Course. IEEE Transactions on Education, 57(1), 25-33.

Appleton, J., Lawrenz, F., Craft, E., Cudmore, W., Hall, J. \& Waintraub, J. (2007). Models for Curricular Materials Development: Combining Applied Development Processes with Theory. Journal of Science Education and Technology, 16(6), 491-499. 
AQU (2014). “Ocupabilitat i competències dels graduats recents: l'opinió d'empreses i institucions”.

Retrieved from http://www.aqu.cat/doc/doc_69192241_1.pdf (Last accessed March 2018).

Arbelaitz, O., Martin, J. I. \& Muguerza, J. (2015). Analysis of Introducing Active Learning

Methodologies in a Basic Computer Architecture Course. IEEE Transactions on Education, 58(2), 110- 116.

Bayer Corporation (2014). The Bayer Facts of Science Education XVI: US STEM Workforce ShortageMyth or Reality? Fortune 1000 Talent Recruiters on the Debate. Journal of Science Education and Technology, 23(5), 617-623.

Bassellier G., Benbasat I., \& Reich, B. H. (2003). The Influence of Business Managers' IT Competence on Championing IT. Information Systems Research, 14(4), 317-336.

Beneitona, P, Esquetini, C., González, J., Maletá, M.M. Siufi, G. \& Wagenaar, R (2007). Reflections on and outlook for Higher Education in Latina America. Final Report - Tuning Latina America Project. University of Deusto and University of Groningen, 2007. Retrieved from http://www.unideusto.org/tuningeu/images/stories/Publications/Tuning_A_Latina_INGL_PR2.pdf (Last accessed March 2018)

Ben-Zvi-Assaraf, O. \& Ayal, N.(2010). Harnessing the Environmental Professional Expertise of Engineering Students—-the Course: "Environmental Management Systems in the Industry', Journal of Science Education and Technology, 19(6), 532-545.

Bloom, B. S., Engelhart, M. D., Furst, E. J., Hill, W. H. \& Krathwohl, D. R. (1956). Taxonomy of Educational Objectives: Handbook I. The Cognitive Domain. New York: David McKay.

Brundtland, G \& The World Comission on Environment and Development (1987). The Brundtland Report: Our Common Future. United Nations General Assembly Resolution 42/187. Oxford University Press.

Cajander, A., Daniels, M. \& von Konsky, B.R. (2011). Development of Professional Competencies in Engineering Education. 41st ASEE/IEEE Frontiers in Education Conference (FIE). Rapid City, SD.

Cano, E. (2012). "El impacto de la evaluación educativa en el desarrollo de competencias en la universidad. La perspectiva de las primeras promociones de graduados”. Internacionalización de la 
I+D. Plan Nacional de I+D+I (2012-2015). Dirección General de investigación y gestión del plan nacional de I+D+i. EDU2012-32766.

Clancy, E., Quinn, P. \& Miller, J. E. (2001). Using case studies to increase awareness of, and improve resolution strategies for, ethical issues in engineering. 31st ASEE/IEEE Frontiers in Education Conference (FIE), Reno, NV.

Crawley, E.F., Brodeur, D.R. \& Soderholm, D.H. (2008). The Education of Future Aeronautical Engineers: Conceiving, Designing, Implementing and Operating. Journal of Science Education and Technology, 17(2), 138-151.

Crawley, E. F., Malmqvist, J., Östlund, S., Brodeur, D. R. and Edström, K. (2014). Rethinking Engineering Education. The CDIO Approach (2nd edition). Springer International Publishing.

European Parliament, European Council (2008). “The European Qualifications Framework (EQF) for Livelong Learning”. Retrieved from https://ec.europa.eu/ploteus/sites/eac-eqf/files/leaflet_en.pdf (Last accessed March 2018).

Evans, R. \& Gabriel, J. (2007). Performing Engineering: How the Performance Metaphor for Engineering Can Transform Communications Learning and Teaching. 37th ASEE/IEEE Frontiers in Education Conference (FIE). Milwaukee, WI.

Gardelliano, S. (2002) UNIDO Competencies. Strengthening Organizational Core Values and Managerial Capabilities. Technical Report, United Nations Industrial Development Organization UNIDO.

Hernando, M., Galan, R., Navarro, I. \& Rodriguez-Losada, D. (2011). Ten Years of Cybertech: The Educational Benefits of Bullfighting Robotics. IEEE Transactions on Education, 54(4), 569-575.

Hodson, D. (1992). Assessment of practical work. Some considerations in philosophy of science. Science \& Education, 1(2), 115-144.

Hu, S. C. (2003). A wholesome ECE education. IEEE Transactions on Education, 46(4), 444-451.

Hu, Q., Li, F. \& Chen, C. (2015). A Smart home test bed for undergraduate education to bridge the curriculum gap from traditional power systems to modernized Smart grids. IEEE Transactions on Education, 58(1), 32-38. 
Jang, H. (2016). Identifying 21st Century STEM Competencies Using Workplace Data. Journal of Science Education and Technology, 25(2): 284-301.

Leuven University, (2005). Guided independent learning A Brochure for instructors" DUO/ICTO (Central Educational Support), University of Leuven. Retrieved from https://blog.associatie.kuleuven.be/petrsu/files/2013/11/brochuregil.pdf (Last accessed March 2018).

Mahan, J. E., Jayasumana, A., Lile, D. \& Palmquist, M. (2000). Bringing an emphasis on technical writing to a freshman course in electrical engineering. IEEE Transactions on Education, 43(1), 36-42.

Mohan, A., Merle, D., Jackson, C. \& Lannin, J. (2010). Professional Skills in the Engineering Curriculum. IEEE Transactions on Education 53(4), 562-571.

Newrock, R. \& Tovar, E. Ed, (2005). Competencies of engineers in Proc. Plenary Sessions of Int. COnf. Engineering Computer education 2005 (IECEC05).

Norton R. E. (1997) DACUM handbook, 2nd ed. Leadership Training Series, 67. The Ohio State University, Center on Education and Training for Employment. Retrieved from https://files.eric.ed.gov/fulltext/ED401483.pdf. (Last accessed March 2018).

O’Connell, R. M. (2015). Adapting team-based learning for application in the basic electric circuit theory sequence. IEEE Transactions on Education, 58(2), 90-97.

Passow, H. J. (2012). Which ABET competencies do engineering graduates find most important in their work? Journal of Engineering Education, 101(1), 95-118.

Pimmely, R. L. (2003). A practical approach for converting group assignments into team projects. IEEE Transactions on Education, 46(2), 273-282.

Quinn, P. (2005). Assessment of a case study laboratory to increase awareness of ethical issues in engineering. IEEE Transactions on Education, 48(2), 313-316.

Rayney V. P. (2002). Beyond technology-renaissance engineers. IEEE Transactions on Education, 45(1).

Riemer, M .J. (2007). Communication skills for the 21st century engineer. Journal of Engineering Education, 11(1), 89-100. 
Shuman, L. J., Besterfield-Sacre, M., and McGourty, J. (2005). The ABET Professional Skills - Can They be Taught? Can They Be Assessed? Journal of Engineering Education, 94(1), 41-56.

Taraman, K. and Tovar, E. Ed (2005). Enhancing the competencies of manufacturing engineers through society of manufacturing engineers- academia-industry partnerships. in Proc. Plenary Sessions of Int. COnf. Engineering Computer education 2005 (IECEC05).

Taylor, E. (2016). Investigating the perception of stakeholders on soft skills development of students: Evidence from South Africa. Interdisciplinary Journal of e-Skills and Life Long Learning, 12, 1-18.

Tribus, M. (2005). Some Remarks on the Improvement of Engineering Education. Journal of Science Education and Technology, 14(1): 1-28.

Villa, A. and Poblete, M. (2008). Competence-Based learning. A proposal for the assessment of generic competences. University of Deusto. Spain.

Wiggins G, McTighe J (1998) Understanding by design. Association for Supervision and Curriculum Development, Alexandria, VA. 